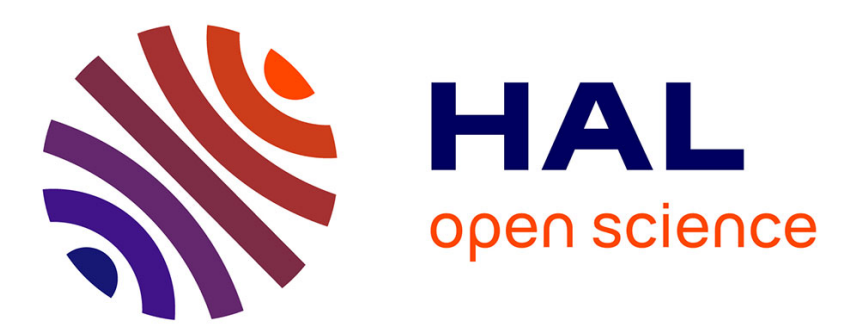

\title{
Acoustic bubbles in therapy: Recent advances with medical microbubbles, clouds, and harmonic antibubbles
}

Michiel Postema, Ayache Bouakaz

\section{To cite this version:}

Michiel Postema, Ayache Bouakaz. Acoustic bubbles in therapy: Recent advances with medical microbubbles, clouds, and harmonic antibubbles. Applied Acoustics, 2018, 140, pp.150-152. 10.1016/j.apacoust.2018.05.002 . hal-02498747

\section{HAL Id: hal-02498747 \\ https://hal.science/hal-02498747}

Submitted on 4 Mar 2020

HAL is a multi-disciplinary open access archive for the deposit and dissemination of scientific research documents, whether they are published or not. The documents may come from teaching and research institutions in France or abroad, or from public or private research centers.
L'archive ouverte pluridisciplinaire HAL, est destinée au dépôt et à la diffusion de documents scientifiques de niveau recherche, publiés ou non, émanant des établissements d'enseignement et de recherche français ou étrangers, des laboratoires publics ou privés. 


\section{Acoustic bubbles in therapy: recent advances with medical microbubbles, clouds, and harmonic antibubbles}

Guest editors:

Michiel POSTEMA ${ }^{1,2,3, *}$, Ayache BOUAKAZ ${ }^{1}$ 


\title{
Acoustic bubbles in therapy: recent advances with medical microbubbles, clouds, and harmonic antibubbles
}

\author{
Guest editors: \\ Michiel POSTEMA ${ }^{1,2,3, *}$, Ayache BOUAKAZ ${ }^{1}$ \\ ${ }^{1}$ Inserm Research Unit U1253: iBrain, Faculté de Médecine, Université de Tours, \\ 10 Boulevard Tonnellé, 37032, Tours, France \\ ${ }^{2}$ LE STUDIUM Loire Valley Institute for Advanced Studies, 1 Rue Dupanloup, 45000, \\ Orléans, France \\ ${ }^{3}$ School of Electrical and Information Engineering, University of the Witwatersrand, \\ Johannesburg, 1 Jan Smuts Laan, Braamfontein 2050, South Africa
}

\section{Editorial}

Although the use of microbubbles has become common in ultrasound diagnostics, microbubbles are not that often seen in therapeutic applications. To share recent advances in the development and application of microbubbles in therapy, LE STUDIUM Loire Valley Institute for Advanced Studies and Inserm Research unit U1253: Imaging and Brain of the University of Tours organised an international conference on this topic. The event was held on 23 and 24 October, 2017, in the Hôtel de Ville of Tours, France, and hosted by Michiel Postema and Ayache Bouakaz from the University of Tours.

Plenary sessions covered a wide range of topics, including bubble physics, bubble acoustic phenomena, bubble engineering and design, in-vitro evaluation, preclinical validations, and clinical studies. The conference was attended by 70 scientists, medical profesionals, and industrial representatives ( $c f$. Figure 1).

The opening session on sonochemotherapy was chaired by Annemieke van Wamel from the Norwegian University of Science and Technology and Michiel Postema from the University of the Witwatersrand, Johannesburg, in residence at the University of Tours. The keynote lecture by Pintong Huang from the Second Affiliated Hospital of Zhejiang University School of Medicine was on 
the antitumour efficacy of ultrasonic cavitation combined with drug-loaded microbubbles when targeting tumour angiogenesis in a fluorescent human colon cancer mouse model [1]. Jean-Michel Escoffre from the University of Tours presented a study on the delivery of cetuximab to colorectal cancer using microbubble-assisted ultrasound [2]. Diane Bressand-Falewee from the University of Tours presented an in-vitro and in-vivo evaluation of the delivery of Nab-Paclitaxel in pancreatic tumours with sonoporation. Spiros Kotopoulis from Haukeland University Hospital lectured on low-intensity sonoporation from lab to patient bedside and elaborated on what we know and where to go from here [3].

Following a live hydrophone demonstration by Andrew Hurrell and Jessica Dendura, both from Precision Acoustics Ltd [4], the session on bubble imaging was chaired by Paul Prentice from the University of Glasgow and Steven Wrenn from Drexel University. Invited speaker Steven Freear from the Universtiy of Leeds spoke about ultrafast plane-wave imaging for nonlinear detection of therapeutic microbubbles [5]. Katrien Vanderperren from Ghent University gave a presentation on contrast-enhanced ultrasound of kidneys in hyperthyroid cats [6]. Erik Verboven from Ghent University presented a study on ultrasound-based dosimetry for radiotherapy, including the in-vitro and in-vivo proof-of-principle.

The session on acoustic cluster therapy was chaired by Katrien Vanderperren from Ghent University and Olivier Couture from the Langevin Institute. The speakers had been kindly invited by Phoenix Solutions. Per Sontum from Phoenix Solutions gave the introductory talk, titled "Acoustic cluster therapy - a novel approach for ultrasound-mediated targeted drug delivery: technology basics and proof of concept" [7]. Invited speaker Annemieke van Wamel from the Norwegian University of Science and Technology showed that acoustic cluster therapy boosts the delivery of drugs in brains and tumours [8]. Invited speaker Paul Prentice from the University of Glasgow spoke of shocking bubbles: cavitation in focussed ultrasound [9]. Keynote speaker Nobuki Kudo from Hokkaido University demonstrated a high-speed observation system for elucidating mechanisms of sonoporation [10].

The session on new insights in therapeutic bubbles was chaired by Benoît Larrat from the Alternative Energies and Atomic Energy Commission and Albert Poortinga from Eindhoven University of Technology. Key-note speaker Eitan Kimmel from Technion - Israel Institute of Technology spoke about acoustics in medicine in view of the intramembrane cavitation model [11]. Vincent Hingot from the Langevin Institute lectured on subwavelength far-field 
ultrasound-targeted drug delivery [12]. Bjoern Gerold from Theraclion discussed the efficiency and safety issues when controlling cavitation in focussed ultrasound surgery [13].

Frédéric Patat from the University of Tours gave an invited public lecture on the many facets of ultrasound, including detecting, seeing, and treating [14]. This lecture was attended by 100 interested people from Tours.

The session on bubbles, antibubbles, and droplets was chaired by Christine Contino-Pépin from the University of Avignon and Charles Sennoga from the University of Tours. Invited speaker Albert Poortinga from Eindhoven University of Technology lectured on a new kind of acoustic bubble, called the antibubble $[15,16]$. Steven Wrenn from Drexel University presented a voltage-activated ultrasound contrast agent for myocardial perfusion imaging [17]. Stéphane Desgranges from the University of Avignon demonstrated stable formulations of perfluorocarbon droplets for tumour detection and treatment [18]. Sigrid Berg from SINTEF and the Norwegian University of Science and Technology spoke about nanoparticle-stabilised microbubbles and ultrasound for enhanced drug delivery [19].

The session on the blood-brain barrier was chaired by Jean-Michel Escoffre from the University of Tours and Spiros Kotopoulis from Haukeland University Hospital. Invited speaker Alexandre Carpentier from Sorbonne University lectured on low-intensity pulsed ultrasound to disrupt the bloodbrain barrier followed by intravenous carboplatin chemotherapy in patients with recurrent brain tumours [20]. Invited speaker Benoît Larrat from the Alternative Energies and Atomic Energy Commission followed with MRI-guided ultrasound-mediated blood-brain barrier opening in non-human primates using passive cavitation detection feedback control [21]. Barbara Cerroni from the University of Rome Tor Vergata spoke about targeting brain tumour vasculature with RGD-decorated microbubbles [22].

Although the posters were on display throughout the conference, a dedicated poster session has held as well. Nigel Bush from the Institute of Cancer Research showed with a poster that acoustic cluster therapy enhances the therapeutic efficacy of Doxil ${ }^{\mathrm{TM}}$ for treatment of triple negative breast cancer in mice [7]. Anastasiia Panfilova from Eindhoven University of Technology had a poster presentation on the relation between contrast-ultrasound kinetic features and microvascular density by acoustic angiography [23]. Katrien Vanderperren from Ghent University presented a poster on renal ageing in cats assessed by contrast-enhanced ultrasound [24] and a poster on the evaluation of renal perfusion using contrast-enhanced ultrasound in cats with chronic 
kidney disease [25]. Letizia Oddo from the University of Rome Tor Vergata showed in a poster the next generation of ultrasound platforms for theranostics [22]. Florian Gailliègue from Institut Gustave Roussy showed a poster with numerical and experimental characterisation of a biochip for sonoporation studies [26]. Emma Kanbar from the University of Tours presented a poster on enhanced subharmonics by acoustic deflation [27]. Simona Turco from Eindhoven University of Technology demonstrated a poster on the pharmacokinetic modelling of targeted microbubbles and the applications thereof in angiogenesis imaging and therapy monitoring [28]. Stéphane Desgranges from the University of Avignon presented a poster on optimised perfluorocarbon nanodroplets for theranostics applications [18]. Nicolas Taulier from the University of Avignon gave a poster presentation on the encapsulation of drugs in perfluorocarbon droplets and drug delivery triggered by HIFU [29]. Nasma Mazzawi from Technion - Israel Institute of Technology showed in a poster the effect of low-intensity ultrasound and MET signalling on cancer cell motility for improved diagnosis and treatment [30]. Jean-Louis Mestas from the University of Lyon 1 presented a poster on doxorubicin delivery in CEM and MDA cell lines without contrast agent [31].

Parallel to the poster session, a representative from La Cellule Mutualisée «Europe-Recherche » gave a presentation on funding opportunities in the EU Horizon 2020 framework programme.

The session on bubble dynamics was chaired by Nobuki Kudo from Hokkaido University and Eitan Kimmel from Technion - Israel Institute of Technology. Invited speaker Alexander Doinikov from Université GrenobleAlpes lectured on the dynamics of bubbles in a confined space [32, 33]. Kristoffer Johansen from the University of Glasgow presented a comparison of single-bubble and cloud models for non-stable cavitation and the emissions generated [9]. Mounir Tarek from the University of Lorraine spoke about the generation and outcome of reactive oxygen species produced by ultrasoundstimulated microbubbles, unraveling a potential mechanism for sonoporation using molecular simulations. Claude Inserra from the University of Lyon 1 showed the threshold, dynamics, and nonlinearity of nonspherical oscillations of gas microbubbles [34, 35].

In conclusion, the conference brought together scientists, medical professionals, and industrial representatives, who shared their most recent findings. We trust that, in the near future, many collaborative projects will be initiated owing to the inspirational multidisciplinary environment and the high scientific level of the presentations at this first conference on acoustic bubbles 
in therapy.

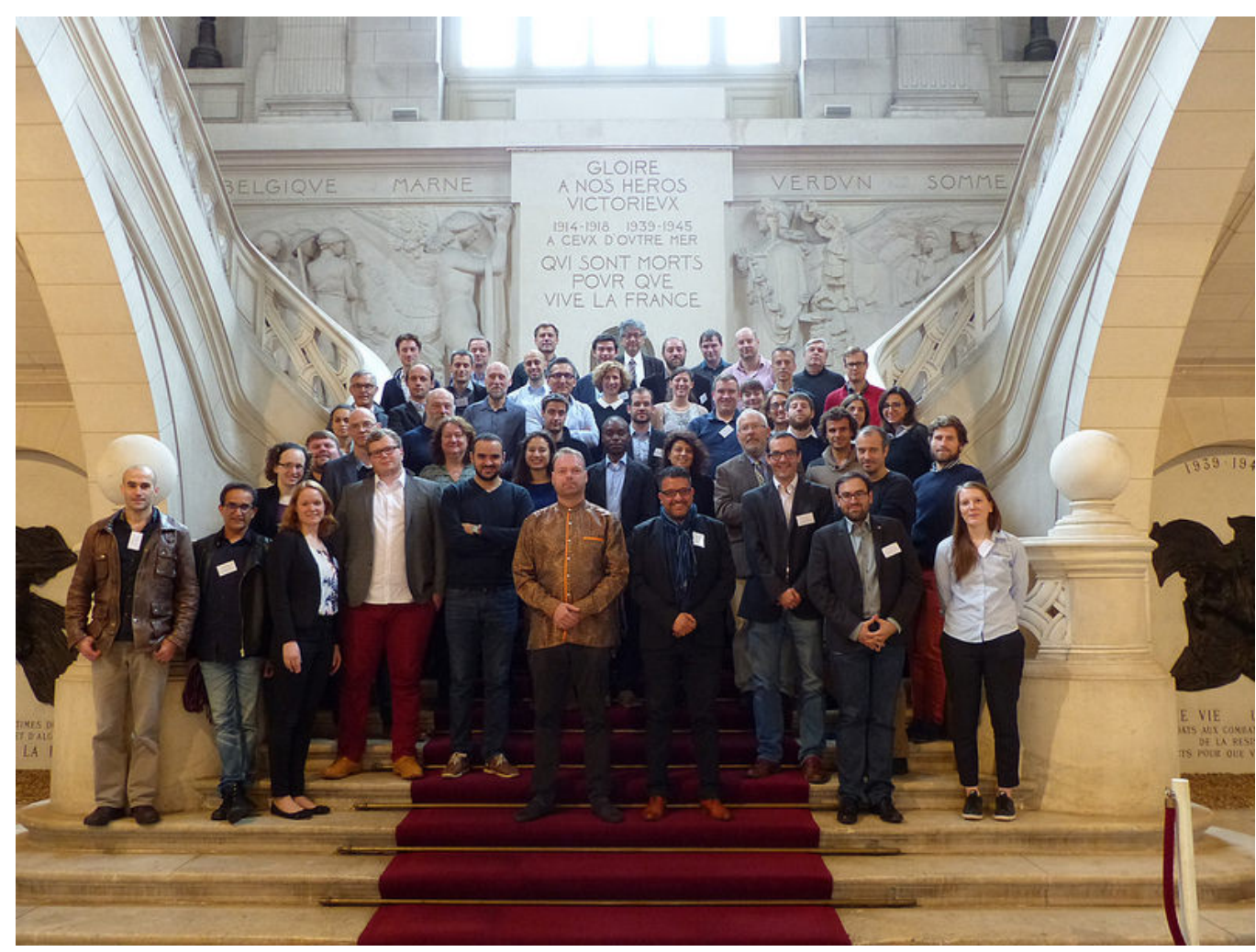

Figure 1: Participants of the first conference on acoustic bubbles in therapy: recent advances with medical microbubbles, clouds, and harmonic antibubbles, Tours, 2017.

\section{Acknowledgements}

The conference was organised by Sophie Gabillet, Maurine Villiers, and Aurélien Montagu, all from LE STUDIUM Loire Valley Institute for Advanced Studies. The organisation received funding from European Union's Horizon 2020 research and innovation programme under Marie Skłodowska-Curie grant agreement No 665790. The conference was supported by a grant from SFR FED4226 de Neuroimagerie Fonctionnelle. In addition, funding was received from the University of Tours, Precision Acoustics Ltd, Phoenix Solutions, IMASONIC SAS, and Vermon S.A.

*Correspondence should be addressed to michiel.postema@wits.ac.za. 


\section{References}

[1] Sun Y, Luo J, Chen J, Xu F, Ding X, Huang P. Ultrasound-mediated microbubbles destruction for treatment of rabbit VX2 orthotopic hepatic tumors. Appl Acoust 2018;138:216-25.

[2] Escoffre JM, Novell A, Serrière S, Lecomte T, Bouakaz A. Irinotecan delivery by microbubble-assisted ultrasound: in vitro validation and a pilot preclinical study. Mol Pharmaceutics 2013;10:2667-75.

[3] Kotopoulis S, Stigen E, Popa M, Mayoral Safont M, Healey A, Kvåle S, Sontum P, Gjertsen BT, Gilja OH, McCormack E. Sonoporation with acoustic cluster therapy (ACT $\cap)$ induces transient tumour volume reduction in a subcutaneous xenograft model of pancreatic ductal adenocarcinoma. J Control Rel 2017;245:70-80.

[4] Hurrell A, Rajagopal S. The practicalities of obtaining and using hydrophone calibration data to derive pressure waveforms. IEEE Trans Ultrason Ferroelectr Freq Control 2017;64:126-40.

[5] McLaughlan JR, Harput S, Abou-Saleh RH, Peyman SA, Evans S, Freear S. Characterisation of liposome-loaded microbubble populations for subharmonic imaging. Ultrasound Med Biol 2017;43:346-56.

[6] Stock E, Paepe D, Daminet S, Vandermeulen E, Duchateau L, Saunders JH, Vanderperren K. Contrast-enhanced ultrasound examination for the assessment of renal perfusion in cats with chronic kidney disease. J Vet Intern Med 2018;32:260-6.

[7] van Wamel A, Sontum PC, Healey AJ, Kvåle S, Bush N, Bamber J, de Lange Davies C. Acoustic cluster therapy (ACT) enhances the therapeutic efficacy of paclitaxel and Abraxane $\mathbb{R}$ for treatment of human prostate adenocarcinoma in mice. J Control Release 2016;236:15-21.

[8] Åslund AKO, Snipstad S, Healey A, Kvåle S, Torp SH, Sontum PC, de Lange Davies C, van Wamel A. Efficient enhancement of blood-brain barrier permeability using acoustic cluster therapy (ACT). Theranostics 2017;7:23-30.

[9] Johansen K, Song JH, Prentice P. Performance characterisation of a passive cavitation detector optimised for subharmonic periodic shock 
waves from acoustic cavitation in $\mathrm{MHz}$ and sub-MHz ultrasound. Ultrason Sonochem 2018;43:146-55.

[10] Isono A, Kudo N. A high-speed microscopic system for observation of bubble-cell interaction from a lateral direction. Proc IEEE Ultrason Symp 2017;17:1-4.

[11] Bukelman O, Krasovitski B, Shapira E, Plaksin M, Postema M, Fox T, Shoham S, Kimmel E. Acoustics in medicine in view of the intramembrane space model (Part I). 2018; to be published.

[12] Hingot V, Bézagu M, Errico C, Desailly Y, Bocheux R, Tanter M, Couture O. Subwavelength far-field ultrasound drug-delivery. Appl Phys Lett 2016;109:194102.

[13] Johnston K, Tapia-Siles C, Gerold B, Postema M, Cochran S, Cuschieri A, Prentice P. Periodic shock-emission from acoustically driven cavitation clouds: a source of the subharmonic signal. Ultrasonics 2014;54:2151-8.

[14] Chaput L, Sallot A, Laurent E, Laure B, Mourtada Y, Georgescou G, Grégoire JM, Ossant F, Maruani A, Vaillant L, Patat F, Machet L. Peut-on faire l'exérèse de tous les mélanomes en seul temps opératoire grâce à l'échographie haute fréquence ? Annales de Dermatologie et de Vénéréologie 2016;143:S174-5.

[15] Poortinga AT, van Rijn CJM. Gas-shell-encapsulation of activated carbon to reduce fouling and increase the efficacy of volatile organic compound removal. Colloid Interface Sci Commun 2017;18:1-4.

[16] Postema M, Novell A, Sennoga C, Poortinga AT, Bouakaz A. Harmonic response from microscopic antibubbles. Appl Acoust 2018;137:148-50.

[17] Cimorelli M, Angel B, Fafarman A, Kohut A, Andrien B, Barrett K, Wrenn S. Introducing a nested phase change agent with an acoustic response that depends on electric field: a candidate for myocardial perfusion imaging and drug delivery. Appl Acoust 2018;138:9-17.

[18] Astafyeva K, Somaglino L, Desgranges S, Berti R, Patinote C, Langevin D, Lazeyras F, Salomir R, Polidori A, Contino-Pépin C, Urbach W, Taulier N. Perfluorocarbon nanodroplets stabilized by fluorinated surfactants: 
characterization and potentiality as theranostic agents. J Mater Chem B 2015;3:2892-907.

[19] Snipstad S, Berg S, Mørch Y, Bjørkøy A, Sulheim E, Hansen R, Grimstad I, van Wamel A, Maaland AF, Torp SH, de Lange Davies C. Ultrasound improves the delivery and therapeutic effect of nanoparticlestabilized microbubbles in breast cancer xenografts. Ultrasound Med Biol 2017;43:2651-69.

[20] Carpentier A, Canney M, Vignot A, Reina V, Beccaria K, Horodyckid C, Karachi C, Leclercq D, Lafon C, Chapelon JY, Capelle L, Cornu P, Sanson M, Hoang-Xuan K, Delattre JY, Idbaih A. Clinical trial of blood-brain barrier disruption by pulsed ultrasound. Sci Transl Med 2016;8:343re2.

[21] Kamimura HA, Flament J, Valette J, Cafarelli A, Aron Badin R, Hantraye P, Larrat B. Feedback control of microbubble cavitation for ultrasound-mediated blood-brain barrier disruption in non-human primates under magnetic resonance guidance. J Cereb Blood Flow Metab 2018;1:271678X17753514.

[22] Oddo L, Cerroni B, Domenici F, Bedini A, Bordi F, Chiessi E, Gerbes S, Paradossi G. Next generation ultrasound platforms for theranostics. J Colloid Interface Sci 2017;491:151-60.

[23] Panfilova A, Shelton SE, Caresio C, van Sloun RJG, Molinari F, Wijkstra H, Dayton P, Mischi M. On the relationship between dynamic contrast-enhanced ultrasound parameters and the underlying vascular architecture extracted from acoustic angiography. Ultrasound Med Biol 2018;submitted.

[24] Stock E, Paepe D, Daminet S, Duchateau L, Saunders JH, Vanderperren $\mathrm{K}$. Influence of ageing on quantitative contrast-enhanced ultrasound of the kidneys in healthy cats. Vet Rec 2018;vetrec-2017-104490.

[25] Stock E, Daminet S, Paepe D, Buresova E, Vandermeulen E, Smets P, Duchateau L, Saunders JH, Vanderperren K. Evaluation of renal perfusion in hyperthyroid cats before and after radioiodine treatment. J Vet Intern Med 2017;31:1658-63. 
[26] Azan A, Gailliègue F, Mir LM, Breton M. Cell membrane electropulsation: chemical analysis of cell membrane modifications and associated transport mechanisms. Adv Anat Embryol Cell Biol 2017;227:59-71.

[27] Kanbar E, Fouan D, Sennoga CA, Doinikov AA, Bouakaz A. Impact of filling gas on subharmonic emissions of phospholipid ultrasound contrast agents. Ultrasound Med Biol 2017;43:1004-15.

[28] Turco S, Tardy I, Frinking P, Wijkstra H, Mischi M. Quantitative ultrasound molecular imaging by modeling the binding kinetics of targeted contrast agent. Phys Med Biol 2017;62:2449-64.

[29] Astafyeva K, Thomas JL, Coulouvrat F, Guédra M, Diou O, Mousnier L, Tsapis N, Urbach W, Taulier N. Properties of theranostic nanoparticles determined in suspension by ultrasonic spectroscopy. Phys Chem Chem Phys 2015; 17:25483-93.

[30] Mazzawi N, Kimmel E, Trasfaty I. The effect of low-intensity ultrasound and MET signalling on cellular motility and morphology. Appl Acoust 2018;submitted.

[31] Chettab K, Mestas JL, Lafond M, Saadna DE, Lafon C, Dumontet C. Doxorubicin delivery into tumor cells by stable cavitation without contrast agents. Mol Pharm 2017;14:441-7.

[32] Doinikov A, Marmottant P. Natural oscillations of a gas bubble in a liquid-filled cavity located in a viscoelastic medium. J Sound Vibration 2018;420:61-72.

[33] Doinikov A, Dollet B, Marmottant P. Model for the growth and the oscillation of a cavitation bubble in a spherical liquid-filled cavity enclosed in an elastic medium. Phys Rev E 2018;97:013108.

[34] Guédra M, Cleve S, Mauger C, Blanc-Benon P, Inserra C. Dynamics of nonspherical microbubble oscillations above instability threshold. Phys Rev E 2017;96:063104.

[35] Guédra M, Cornu C, Inserra C. A derivation of the stable cavitation threshold accounting for bubble-bubble interactions. Ultrason Sonochem 2017;38:168-73. 